neuroleptic malignant syndrome, and this presentation of carbon monoxide poisoning led us to treat the patient with dantrolene,' with good effect. Thermogenesis was probably due to skeletal muscle rigidity, and the relaxant action of dantrolenc produced a fall in temperature as a secondary henefit.

(Our patient mas have recovered spontaneously, but the responses to dantrolene merit notice. Further investigation is needed to see whether dantrolene is effective in treating severe cases of carbon monoxide poisoning. Moreover, its use in other hypermetabolic states could be beneficial.

I (iuæc BH, Baxter LR. Ncurokptic malignant svndrome. N Engl f Med 1985;313:163-6.

? (lark (J, Campbell D, Reid W'II. Blıxl carbuxvhacmoglobin and cyanide levels in fire survivors. l.ancet 1981;i:1332-5.

3 Dolan MC Carbon monoxide puixuning Cim. HI cd Assoc f 1985;133:392-9.

+ Mvers RA, Linherg SL: Cowler KA. Carbon monoxide poisoning: the injury and its treatment.

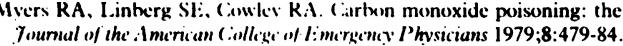

Boutros AR, Hovt JI. Management of carbon monoxide poisoning in the absence of hyperbaric oxvgenation chamber. (int Ciarc. Mled 1976;4:144.

Licipted 8 Fichruan 1988)

Department of Neurology, St Elisabeth Hospital, Postbox 90151, 5000 LC Tilburg, The Netherlands

J B M TEN HOLTER, MD, registrar

R L L A M SCHELLENS, MD, senior neurologist

Correspondence to: Dr Ten Holter.

\section{Photosensitive epilepsy in children who set fires}

The flickering light of television is recognised as epileptogenic. Some children with photosensitive epilepsy find viewing television compulsively attractive' and even induce seizures by viewing it (C D Binnic, Compliance in epilepsy, Salzburg, 1987). Flames may be a self induced stimulus in those children with photosensitive epilepsy who repeatedly set light to things (fire setting).

\section{Case reports}

CASE 1

A man aged 31 had his first attack of epilepsy at the age of 7 , when he saw "hundreds of tiny silver dots, then blackness." Minutes later his sight returned. He had innumerable similar attacks for eight years. As his vision cleared he was overtaken by anger and violence commonly followed: he punched bystanders, broke windows, and burned sheds and hedgerows. Recognising the sequence, he tried to limit the damage, running off alone whenever he saw the silver dots.

His behaviour antagonised his parents. He was seen in child guidance clinics, put on probation, taken into care, placed in children's homes, and sent to approved schools, but his disruptive behaviour continued, of ten after viewing television. At age 13 his epilepsy was diagnosed. Electroencephalography without photic stimulation showed diffuse abnormalities, arrhythmia and sharp and slow components that were maximal in the posterior left temporal region. Although prescribed phenvtoin, he palmed the tablets. His attacks stopped withou treatment at age 15, and electroencephalographs were subsequently normal.

\section{(CASE 2}

From babvhood the 6 year old daughter of the man in case 1 had thrown paper on to fires and watched it hurn. She set fire to her toys, singed her rabbit's fur, posted lighted matches through the letterbox, and fused an electric circuit with burning papers. She watched television from a distance of $50 \mathrm{~cm}$ with maximum colour and contrast. Her mother noticed repeated short episodes, while she was viewing television when she suddenly stared at the wall, white faced and withdrawn. Tears or pranks followed; once she set fire to the sofa. Epilepsy was suspected, and while awaiting neurological investigation she stole a cigarette lighter. Her father, fearing a fire, eaned her, and she was admitted to hospital. Compulsory care proceedings were started. (On transfer to another hospital an electroencephalogram showed typical photoconvulsant responses during photic timulation at flash rates above 10 cveles/second, particularly with red and orange light; the recording was otherwise normal. She returned home and complied with instructions to stay three metres from the television screen. ' Her behaviour was exemplary. Three months later a $2 t$ hour ambulatory electroencephalogram showed that abnormalities occurred immediately when she viewed television from her former position.

After six months of normal behaviour her parents reported renewed moodiness, then discovered eaches of spent matches. Meanwhile her teachers, misled by her episodic pallor and abstraction, suspected parental cruelty. Electroencephalography showed sensitivity to fluorescent light, to which she was exposed at school, and to patterns. She was admitted to hospital for drug treatment under electroencephalographic control. Photic spikes lessened with phenytoin, returned with carbamazepine, then disappeared with sodium valproate $200 \mathrm{mg}$ twice daily. She continued to take this drug, and her behaviour was normal during the next six months.

\section{Comment}

Fire setting and photogenic epilepsy might coexist by chance but were closely linked in these two cases. The aggressive conduct of the patient in case 1 followed his seizures, and he continued to set fires until he outgrew his epilepsy. His daughter (case 2) behaved normally after avoiding the photic stimulus of close viewing of the television. She began to set fires again in response to photic stimulation by fluorescent lights. Both her fire setting and electroencephalographic abnormalities resolved on treatment with sodium valproate.

Fire setting inevitably causes family disturbances, and blaming the child or the family may lead to inappropriate attempts at containment instead of treatment. Sensitivity to television as a cause of epilepsy is easily missed because the family watches the screen, not each other. Flames lit during preictal compulsion or postictal confusion may kindle further epilepsy." Those who set fires, particularly younger, solitary children, ${ }^{4}$ should undergo electroencephalography.

We thank Professor V Dubowity for allowing publication of case 2; Oxford Medical Systems for the loan of an ambulatory electroencephalographic recorder; and Elizabeth Wallace of the British Epilepsy Association for helpful advice.

I Jeavons P'M. Harding (jFA. P'hotosensiture epilensy. London: W'illiam Heinemann, 1975.

2 Anonymous. Telerision-induced epilepsy and its presention. [Lditorial.| Br .Med 7 1978: 1 : 301 1-2.

2 Anonmous. Felecision-induced epilepsy and its presention. [Editorial. Fr. Ited f 1978:1:1301-2.

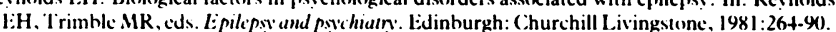

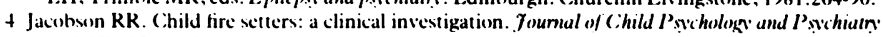
and 1 llicd Disciplines 1985:26:759-68.

licipled 2. March 1988

Surgery, Clifton Hampden, Oxfordshire OX14 3EJ

ELIZABETH A MEINHARD, MD, FRCPATH, general practitioner

Hammersmith Hospital, London W12 0HS

ROWENA OOZEER, chief technician in electroencephalography DUNCAN CAMERON, MRCP, 1)CH, registrar in paediatrics

\section{An offer of rheumatology training: failure to influence clinic referrals}

It has been suggested that teaching of small groups of general practitioners by consultants in the general practitioners' surgeries may be a more useful approach than lectures to large audiences in hospitals.' Such teaching can influence the behaviour of general practitioners volunteering for educational sessions, ${ }^{2}$ but education does not necessarily decrease the demand for specialist opinions. ${ }^{3}$ This study reports the responses of general practitioners referring patients with soft tissue lesions of the shoulder and elbow when they were offered individual clinical tutorials by a consultant.

\section{Patients, methods, and results}

From 1 August 1984 until 31 July 1987 every general practitioner who referred a patient with an uncomplicated soft tissue lesion of the shoulder or elbow to a rheumatology clinic was sent an offer of individual teaching by a consultant with the relevant patient's clinic letter. This offer suggested that should the general practitioner have any further patients with shoulder or elbow lesions he or she should contact the consultant, who would come to the surgery and, with the general practitioner, examine, diagnose, and, where appropriate, inject the patient's soft tissue lesion. Further letters were sent to the general practitioners after each subsequent referral. These educational offers had no implications with respect to section 63 or domiciliary visit payment. In all 120 offers were made (19 in relation to elbow and 101 in relation to shoulder lesions) to a total of 41 principals and four trainees. Twenty two doctors received two or more offers, and six sessions were arranged, with nine general practitioners receiving teaching.

A lunchtime meeting entitled "shoulder pain-the GP's role," accounting for half of a section 63 session, was organised two and a half years after the start of the study at this hospital, and all general practitioners in Leeds were invited to attend. The potential effects of the educational exercise on clinic load were examined by observing how many referrals in the last six months of the study might have been avoided if general practitioners who had received two or more educational offers had responded to them and managed the patient themselves. 